\title{
Whose standard is it, anyway? How the tobacco industry determines the International Organization for Standardization (ISO) standards for tobacco and tobacco products
}

\author{
Stella A Bialous, Derek Yach
}

\begin{abstract}
Objective-To describe the extent of the tobacco industry involvement in establishing international standards for tobacco and tobacco products and the industry influence on the International Organization for Standardization (ISO).

Methods-Analysis of tobacco industry documents made public as part of the settlement of the Minnesota Tobacco Trial and the Master Settlement Agreement. Search words included "ISO", "CORESTA", "Barclay", "compensation and machine smoking", "tar and nicotine deliveries", and the name of key players, in different combinations.

Results-It is clear that the tobacco industry, through the Cooperation Centre for Scientific Research Relative to Tobacco (CORESTA), play a major role in determining the scientific evidence and suggesting the standards that are eventually adopted as international standards for tobacco and tobacco products in several areas, including the measurement of cigarette tar and nicotine yield.

Conclusions-ISO's tobacco and tobacco products standards are not adequate to guide tobacco products regulatory policies, and no health claims can be made based on ISO's tobacco products standards. There is an urgent need for tobacco control advocates and groups worldwide to be more involved with the work of the ISO, both directly and through their national standardisation organisations. (Tobacco Control 2001;10:96-104)
\end{abstract}

Keywords: tar and nicotine measurement; International Organization for Standardization; ISO; Cooperation Centre for Scientific Research Relative to Tobacco; CORESTA; regulatory policy

Tobacco Free Initiative, World Health Organization, Geneva, Switzerland S A Bialous

D Yach

Correspondence to: Stella Aguinaga Bialous, 676 Funston Avenue, San Francisco, CA 94118, USA stella@bialous.com

Received 12 July 2000 and in revised form

6 February 2001. Accepted 7 February 2001
Standards play a key role in the regulation of consumer products. Regulatory agencies throughout the world use standards to evaluate whether or not a product is in compliance with the desirable consumer safety features, and manufacturers worldwide display the seal of approval of the country's national standardisation office or the International Organization for Standardization (ISO) as a symbol of quality.

The ISO, established in 1947, is a "worldwide non-governmental organisation of national standards bodies from some 130 countries" with a mission to "promote the development of standardisation and related activities in the world with a view to facilitating the international exchange of goods and services, and to developing cooperation in the spheres of intellectual, scientific, technological and economic activity." ISO standards are used in the development of policies, regulation, and legislation of health and safety matters on a variety of issues.

ISO is made up of its members, which are divided into three categories:

(1) a member body of ISO is the national body "most representative of standardisation in its country", and there is only one member body per country. Member bodies have the right to be represented on a committee;

(2) a correspondent member is an "organisation in a country which does not yet have a fully developed national standards activity". Correspondent members "are entitled to be kept fully informed about the work of interest to them";

(3) subscriber membership, "for countries with very small economies."

Some 2850 technical committees, subcommittees, and working groups carry out the technical work of ISO. Representatives of industry, research institutes, government authorities, non-government organisations, consumer bodies, and international organisations from all over the world participate, directly, in liaison with ISO, or indirectly, through a national member body, in the work of these committees and the development of international standards. (ISO's member bodies are national standards institutions, which in turn have varying degrees of affiliation with their governments, depending on the country.) ${ }^{1}$

The need to develop a standard is usually initiated by an industry sector. Standards result from "consensus agreements reached between all economic players in that industrial sectorsuppliers, users, and often government." One of the aims of standards is "to facilitate trade, exchange and technology transfer through... improved health, safety and environmental protection, and reduction of waste." ${ }^{11}$ It is important to question if these aims are being met in the case of tobacco and tobacco products standards.

It has been known for decades that the standard ISO measurement to determine tar and nicotine yield (and the slightly different 
US Federal Trade Commission (FTC) method) does not reflect the amount of tar and nicotine delivered to the smoker, a fact that is acknowledged in several published studies, including studies funded by the tobacco industry. $^{2-6}$ Both the ISO and the FTC methods, as well as Germany's DIN method, are derived from CORESTA Standard Methods 10 and 12-tar and nicotine determination in cigarette smoke. ${ }^{7}$ The methods use a smoking machine to measure the deliveries of these components and were developed to provide a ranking of tar and nicotine yields, and not to determine the health consequences or the amount actually delivered to a smoker. The method specifies the volume and duration of puff over a certain amount of time. ${ }^{8-10}$ There are a few differences between these methods that leads to variation in the yield of tar and nicotine measured for the same cigarette brand. Among other differences, the ISO method uses different conditions for smoking, such as temperature, different drafts on the smoking machine, and different cigarette butt length. ${ }^{11-14}$

In addition, cigarette design has been used to "cheat" the smoking machine, providing lower tar and nicotine readings by machine versus human smoking, a fact that has also been widely discussed in the scientific literature. The accompanying misleading labels that claim a cigarette brand is "mild" or "light" and how smokers "compensate" lower yields by changing the manner they smoke, has also been amply discussed, including by the tobacco industry itself. ${ }^{4-6891516}$ The FTC, in its proposal to review the cigarette testing methodology, states that the "compensatory smoking behaviour substantially reduces the informative value of the current [tar and nicotine] ratings" and that more accurate information should be provided to consumers. ${ }^{8}$

Like the FTC method, the ISO method can be useful for some ranking in terms of tar and nicotine yield as measured by machine smoking procedures, but it can not be used for consumer information or claims in terms of tar and nicotine actually delivered to the smoker. No health claims can be made based on the ISO/FTC tar and nicotine cigarette yield measurements. Indeed, when the FTC method was adopted, in 1967, it was not to determine "the amount of 'tar' and nicotine inhaled by any human smoker, but rather to determine the amount of tar and nicotine generated when a cigarette is smoked by a machine in accordance with the prescribed method." ${ }^{\text {Nonetheless, }}$ ISO standards continue to be used in regulatory and policy settings, and public health concerns continue to be inappropriately mentioned as reasons to lower tar and nicotine yield in cigarette smoke as measured by machine smoking methods. In June 2000 the European Union (EU) started the approval process of a directive that determines new, lower limits of tar, nicotine, and carbon monoxide deliveries based on ISO measurements, ${ }^{17}$ despite commentaries from health groups pointing to the inadequacy of the ISO method. ${ }^{18}{ }^{19}$ Although the EU recognised that all cigarettes are harmful, including those with lower tar and nicotine yield, it stated that tar, nicotine, and carbon monoxide ceilings, as measured by ISO methods (for lack of another international standard and until a better standard is developed), were necessary to "ensure high levels of public health protection." ${ }^{\text {"17 }}$ (As of March 2001 the directive has not yet been through all the steps of the approval process, but it is moving rapidly in that direction.)

Considering the massive amount of evidence showing that ISO standards on tobacco and tobacco products are inadequate for health protection purposes, and indeed they were not meant to serve as a health and safety standard, one is puzzled by the fact that there has been no concerted worldwide effort by government and non-government agencies to develop and propose more appropriate performance standards - that is, standards that will permit a better assessment of the cigarette smoke components delivered to the smoker. Among options to address the issue are: on the one hand, as a precautionary measure, the refusal to consider standards that make no provision for health concerns (such as the current ISO standard) when developing regulatory, health related policies and legislation, thus no longer perpetuating the "low tar, low nicotine" myth; and on the other hand, there is the option of increased participation in the work of ISO. So far, health groups and health agencies have largely underestimated the importance of conveying their views and concerns to ISO's committees and thus have failed to counter the influence of the tobacco industry on ISO. However, change might be forthcoming with an increase worldwide interest in the regulation of tobacco products. The final report ${ }^{20}$ from the World Health Organization (WHO) sponsored meeting "Advancing knowledge on regulating tobacco products", held in Oslo, Norway in February 2000 to discuss international regulatory issues, acknowledges the inadequacy of using ISO/FTC measurements to determine the health impact of cigarettes, and recommends that measures of tar and nicotine derived from ISO/FTC methods be removed from cigarette packages because of their misleading influence in a health perspective. ${ }^{2021}$

The issue of standard measurement of tobacco products components is likely to gain even more international visibility as the negotiations for the Framework Convention for Tobacco Control advance and include the regulation of tobacco products among its protocols. As these initiatives move forward, it is important for public health professionals to understand the purposes of such standards and to use them accordingly. ${ }^{22} 23$

This paper describes the extent of the tobacco industry involvement in establishing international standards for tobacco and tobacco products.

\section{Methods}

We analysed the contents of tobacco industry documents made public as part of the settlement of the Minnesota Tobacco Trial and 
the Master Settlement Agreement. We searched both tobacco industry and nontobacco industry websites that placed these documents on the internet. Search words included "ISO", "CORESTA", "Barclay", "compensation and machine smoking", "tar and nicotine deliveries", and the name of key players, in different combinations.

\section{Results}

Industry participation in the development of ISO standards is not exclusive to tobacco, but unlike other products, such as screws and credit cards, the determination of standards by the industry, without the participation of other interested parties, has lead to the development of standards that protect the political and commercial interests of the industry rather than those of the consumer. In the case of ISO technical committee 126-tobacco and tobacco products standards (ISO TC/126, established in 1968), the standards are developed in fact by the Cooperation Centre for Scientific Research Relative to Tobacco (CORESTA).

CORESTA

CORESTA began in 1955 as a research organisation of industry tobacco chemists from around the world. Its membership is dominated by the tobacco industry, including both state monopolies and multinational companies. ${ }^{24-27}$

CORESTA's scientific activities aim to advance the interests of the tobacco industry worldwide, ${ }^{28}$ and to pre-empt regulations through the development of its own research and standards..$^{29}{ }^{30}$ For example, a letter from Philip Morris (PM) vice president of international operations services, Manuel Bourlas, to CORESTA's secretary general François Jacob in $1992^{31}$ stated:

"I believe in and continue to support the concept of a collaborative effort in addressing scientific problems related to tobacco as the concept tends to strengthen the industry's position in the scientific world ...

"I am certain that we could develop a global scientific program which would go beyond the development of measurement techniques while at the same time remain sensitive to proprietary and competitive issues." ${ }^{\prime 1}$

CORESTA is one of the many international bodies that work in liaison with ISO. ${ }^{32}$ The standards developed under the aegis of ISO/TC 126 are based on the tests and scientific evidence provided by CORESTA. Most individuals involved in the work of ISO/TC 126 are tobacco industry representatives. ${ }^{33}{ }^{34}$ At the 1995 ISO/TC 126 plenary meeting in South Africa, of the 52 individuals present, only seven people identified themselves as representing their national standards body, plus the two people of TC 126 secretariat-the German DIN. ${ }^{34}$ As stated in a 1993 letter from PM Europe research and development employee, JB Boder, to Manuel Bourlas, PM senior manager:

"There are two international organizations controlled by the industry: CORESTA and ISO ... CORESTA which is $100 \%$ controlled by the industry . . ISO technical committee 126 is made of approximately $80 \%$ Industry ... The best way to work with these two organizations is to do all the technical work within CORESTA and then have it endorsed by ISO."24

CORESTA conducts its work on tobacco products standards through one of several mechanisms: suggesting new standards and work items, ${ }^{33}{ }^{356}$ revising current standards ${ }^{32}$ or responding to ISO's request for research in the establishment of a new standard. ${ }^{37}{ }^{38}$ Draft standards prepared by CORESTA are eventually circulated to the technical committee's member bodies for approval and standards are approved as recommended by CORESTA, with limited opportunity for significant amendments. For example, the minutes of a CORESTA's environmental tobacco smoke (ETS) subgroup meeting in Paris in April 1997 state:

"The draft international standard ISO/DIS 11454 'Tobacco and tobacco productsdetermination of vapour-phase nicotine in air - gas chromatography method' was approved and will be published without change, other than editorial, as an international standard. (This standard is technically the same as CORESTA recommended method 14)." ${ }^{39}$

This arrangement is favourably perceived by the tobacco industry. As per a document describing the technical committee 126:

"It is unnecessary to describe CORESTA in detail. Suffice to say that the relationship with ISO/TC 126 is such that CORESTA does the science and the collaborative testing and produces recommended methods which are subsequently submitted for conversion into International Standards. If a work proposal is accepted by ISO/TC 126 and study is required, it is almost always referred to the appropriate study group in CORESTA. This procedure has worked extraordinarily well in the revision of ISO 3308, 3402, 4387,8243 and the issue of 10315 and $10362 . .^{33}$ The chairperson of technical committee 126 is PI Adams, who used to work for Imperial Tobacco Ltd, ${ }^{40}{ }^{41}$ is credited with the invention of a type of ventilated filter, ${ }^{42}$ served as president of CORESTA's technology group, ${ }^{43}$ and is listed as an "industry consultant" to the Tobacco Manufacturers Association. ${ }^{44} 45$

In addition to methods for measuring tar and nicotine yield, CORESTA also provides ISO with research to establish standards in other areas such as: methods for determining organochlorine pesticides residues, ${ }^{46}{ }^{47}$ methods for preparation, conditioning, and sampling of fine cut tobaccos and smoking articles, ${ }^{46}$ analysis of genetically modified tobacco, ${ }^{47-50}$ and determination of nicotine in ETS through gas chromatographic methods. $^{5152}$

Moreover, CORESTA conducts research in preparation for future standard needs in the areas where there has not yet been enough agreement within the industry that standards are needed. Such areas include ETS components and non-smoker exposure to these components, ${ }^{5153}$ cigar, pipe, and cut tobacco smoking, and roll-your-own (RYO) cigarettes, among others. ${ }^{46} 495154$

CORESTA works with ISO either directly or through one of ISO's member bodies, such as 
the British Standard Institute (BSI) or American National Standards Institute (ANSI)..$^{32455}$ (At a CORESTA's ETS subgroup meeting in Paris in April 1997 it was stated that ultraviolet absorbance and fluorescence methods described in document ISO/TC $126 \mathrm{~N} 554$, "Environmental tobacco smoke-estimation of the contribution to respirable suspended particles-ultraviolet absorbance and fluorescence methods" would be accepted by ISO as a new work item and that Mike Ogden, from RJ Reynolds (RJR) tobacco research and development department would be confirmed as project leader. ${ }^{39}$ ) For example, Helmut Reif's (from PM worldwide scientific affairs) monthly report for May 1998, ${ }^{56}$ described the "regular meeting of the scientific commission of CORESTA" and stated:

"... a method for ETS determination (quantification by UVPM and FPM) sent via ANSI (M Ogden) to ISO. It was seen necessary to make it clear in a preamble that this method would only be able to determine RSP that stem from any combustion process and therefore cannot be seen as specific for ETS. ${ }^{56}$

CORESTA expanded from a mere scientific entity to become more involved in political issues that concern the industry, such as regulatory policies, ${ }^{38} 57$ but there was apprehension that by becoming too politically involved CORESTA's scientific credibility could suffer, ${ }^{58}{ }^{59}$ particularly in the area of pesticides. Nonetheless, the 1983 minutes of the scientific committee states, "thanks to the pesticide subgroup, the industry was in a better position for discussion with the regulatory authorities." 60 And in a 1989 report of a CORESTA board meeting in Rome, where a review of smoking procedures methods was discussed, PM's Manuel Bourlas stated that:

"The situation today however, is that 'regulatory authorities' DO play an important role in the analytical methods which are used and play an even larger role in 'printed numbers'." [emphasis on original $]^{61}$

NON-CORESTA PARTICIPATION IN ISO TC 126 ISO's member bodies are entitled to participate and exercise full voting rights on any technical committee and policy committee of ISO. A member body takes the responsibility for "informing potentially interested parties in their country of relevant international standardisation opportunities and initiatives: and "ensuring that a concerted view of the country's interests is present during international negotiations leading to standards agreements." Despite the stated openness for input from interested parties, CORESTA resists any interference with its proposed standards, and make efforts to keep overall control of the situation and the outcomes of ISO meetings. For example, the minutes of CORESTA's outgoing scientific commission meeting in Japan in 1996 stated:

"The subgroup routine analytical chemistry has prepared a series of editorial updates of the smoking methods. Shortly before the ISO meeting in Williamsburg in October 1996, the British body (BSI) sent a number of proposals on the same topic and at the meeting it was clear that some non-CORESTA participants, in particular government labs, were eager to have their say, with the support of ISO itself.

"After the meeting of ISO, it is clear that if the CORESTA methods and ISO standards are to remain close or identical, it is not desirable to publish revised CORESTA methods immediately, but to hand out a draft and wait for eventual ISO amendments, then publish a revised version very close to the ISO revised standard. $"{ }^{57}$

Further, while addressing the issue of standards for RYO, the same minutes stated: "At the ISO meeting, the matter of participation of non-CORESTA bodies to the experimental work was raised and has to be addressed." ${ }^{57}$ The proposed solution to this "outsider" participation was that after methods have been determined by CORESTA, a subgroup will work on the validation of the methods, at which stage "outside bodies such as government labs could then be invited to participate ..."57 (The industry was concerned that problems with reaching an agreement over methods for measuring RYO tar and nicotine yield would lead to a cooperation with government laboratories. ${ }^{48}$ )

CORESTA AND ISO RELATIONS WITH WHO AND OTHER ORGANISATIONS

ISO has official status as a non-governmental organisation with WHO, which provides the tobacco industry, through ISO/TC 126 , access to WHO and the United Nations' Food and Agriculture Organization (FAO). (In addition, WHO has an observer status with ISO, and CORESTA has an official "liaison" with FAO.)

In 1990 one of CORESTA's consultants was a Dr Vetorazzi, an asset to the industry as he was "personally acquainted to most of the main players in the $\mathrm{WHO} / \mathrm{FAO}$ business, due to his former assignment as secretary of the joint working group . .."38 and who due to his old contacts "can approach all files of WHO, even the classified ones ..." while he was working on pesticide issues for CORESTA. ${ }^{38} 58$ In 1993, while still working as a CORESTA consultant, Vetorazzi was an invited temporary advisor on the joint FAO/WHO meeting on pesticides residues. ${ }^{62}$ (The tobacco industry interest in FAO is, at least partly, out of concern with pesticide use and pesticide residues allowance regulations. CORESTA's involvement with FAO on pesticides residue regulations intensified in $1974 .^{63}$ Pesticides residues allowances are a concern of the industry because they are usually based on leaf residues and not on health effects of the residues in the final product-cigarette. This often leads to lower levels allowed than desired by the industry.)

In addition to WHO and FAO, ISO/TC 126 also participates in other multisectoral collaboration of the United Nations agencies on issues of tobacco and health, providing information about the works of ISO/TC 126 to, for example, the United Nations Conference on Trade and Development (UNCTAD). ${ }^{27} 34$

Although CORESTA represents the industry, individual companies also develop their own strategies to protect their commercial interests in the face of standards and 
regulations. An example is PM's "Europe science and technology defensive activities for 1983-1988" that list, among others, objectives and strategies to contact scientists and officials, including at WHO, to "learn about their intentions, to modify their opinions, to precede their interventions with national government agencies ..." ${ }^{64}$ to extend and deepen PM's position within CORESTA, and:

"Further deepening of contacts by PM experts with standardizing organisations and with institutions that carry out control measurements on cigarettes, ingredients, or other relevant commodities in order to assure that $P M$ products are measured correctly throughout the world, and that they find universal acceptance.

"Strategies: Initiative by PM representatives in directing the activities of the International Standards Organization (ISO) and the various national standardizing committees in the PM sense as well as actively collaborating in joint experimentations with national testing organisations (e.g. LGC, Canton Chemists, BGA) so as to assure that $P M$ methodology, PM instrumentation, PM laboratory practices find the widest possible acceptance, and that PM products are tested in a fair way." ${ }^{\prime 64}$ [emphasis in original]

In 1990, PM continued to attempt to grow its influence in the works of ISO and CORESTA and wanted these organisations to:

“. . . provide better support for the Industry (and PM) by taking a more aggressive position in the technical/scientific tobacco environment. Without implying that they should jump into the smoking and health controversy, I think there are many issues which they could handle with good chances of success. For example:

- Tolerated pesticide residues levels

-Approved tobacco additives

-ETS studies

-Approved packaging materials

-etc ..."24

PHILIP MORRIS VERSUS BRITISH AMERICAN

TOBACCO: THE LOW TAR DEBATE

One of the areas where ISO standards have best served the industry is through providing the impression of legitimacy to industry claims that cigarettes with lower levels of tar and nicotine yield were less harmful. ${ }^{6}{ }^{16}$ A discussion over one particular low tar claim led to one of the largest "insider" battles of the tobacco industry.

Although in the area of standards, the tobacco companies tend to agree, this agreement is not always easily reached. Commercial interests and proprietary issues often create conflict in the work of CORESTA and ISO. One of such disagreements occurred in the early 1980s, over whether or not British American Tobacco (BAT) channel ventilated cigarettes should be submitted to the same analytical tests as non-channel, conventionally ventilated cigarettes. (Channel ventilation was a design that brought additional airflow into the cigarette filter.) Conventionally ventilated filters dilute mainstream smoke through a variety of mechanisms, used alone or in combination, mainly: creation of holes in the filter itself, increased air permeability, and porosity of the paper used to wrap the filter and the tip of the cigarette, all part of the filter itself and with the intent of creating holes in the filter. ${ }^{65}{ }^{66}$ Holes in cigarette filters were invented to "cheat" smoking machines that measure tar and nicotine yield, by allowing air to flow into the machine and diluting the concentration of cigarette smoke components. It has been demonstrated that human smokers compensate for lower delivery by, among other things, blocking those holes. $^{23}{ }^{15}$ Channel ventilated cigarettes were able to yield even lower tar reading through the standard smoking machine method (ISO/DIS 4387) by bringing additional fresh air in the smoke through its channels. These cigarettes used the:

“. . . so-called 'Actron' filter which provides ventilation through four peripheral channels which are isolated from the core of the filter. When a human being smokes this cigarette, his lips inevitably block some of the peripheral channels, so that the cigarette delivers significantly greater amounts of tar when smoked by human beings than when tested on a smoking machine." ${ }^{67}$

BAT marketed the new product, Barclay, as an "ultra-light" cigarette with only $1 \mathrm{mg}$ of tar. (The reported $1 \mathrm{mg}$ of tar was actually $5 \mathrm{mg}$ when the channels in the filter were blocked. ${ }^{68}$ )

PM protested that BAT could not market its products based on a reading by a method not appropriate for channel ventilated filters. It considered channel ventilation a "leakage" (false air entering the cigarette holder) rather than "ventilation" (dilution). ${ }^{7}$ BAT's argument was that:

“. . all ventilated cigarettes produce higher deliveries during human smoking than during machine smoking, and that even though this difference is greater in channel-ventilated cigarettes it is not reason enough to treat these cigarettes differently. ${ }^{69}$ [emphasis on original]

The industry documents addressing the BAT/PM disagreement provide insight on how aware the cigarette companies were that by creating a special type of filter they were able to reduce the readings of tar and nicotine without compromising the taste of the cigarette. ISO meetings became the arena for the BAT and PM battle. The debate over adequacy the testing methods for the channel ventilated cigarettes started at an ISO meeting in Paris in September $1985,{ }^{70}$ continued in 1986 in Turkey, ${ }^{69}{ }^{71}$ and 1988 in China. ${ }^{72}{ }^{73}$ By 1989, an agreement was reached between the two companies. It was agreed that CORESTA would work on developing a new testing method that would address issues related to measuring yield in channel ventilated cigarettes (without changing measurements of "conventional" cigarettes), and that both companies would work toward "a smooth and rapid adoption of the new method" ${ }^{74}$ It was also agreed that PM would stop litigation in regards to Barclay. It was not a change in the yields of either conventional or channel ventilated cigarettes, but a rather an agreement on how the data would be reported. ${ }^{74-76}$

Measurement methods continued to be a commercial and operational concern for the industry. Indeed, a 1990 PM memo discussing the fact that a few countries have their own measuring standards stated: 
"Tar delivery of cigarettes depends upon the smoking method used, and no one method can be said to be more correct than another.

"As a result of this lack of agreement on a standard smoking method, governmental regulators within each country have arbitrarily defined standard smoking method for their country to provide consumers with a relative ranking of tar delivery of cigarettes and to regulate the advertising of cigarettes. As an example of the magnitude of these different methods, the tar delivery of a full flavoured Marlboro will vary by as much as $2 \mathrm{mg}$, depending upon the smoking method used. This becomes critical in those countries where we are required to print tar delivery on the packs and the tar delivery is verified by "official" governmental laboratory ...

"If we accept the $2 \mathrm{mg}$ lower limit as in this Standard [ISO/DIS 4387], we run the risk of losing the ability to advertise a product as $1 \mathrm{mg}$ in those countries that do not have a "regulatory authority" to confirm the data . .

"If we are successful in developing new ISO methods that are adopted by the EEC countries, it should also be adopted by the other countries that follow ISO standards. I would recommend that PM work towards having the ISO smoking methods adopted by those countries that do not traditionally follow ISO standards. This includes US, Japan, Gulf Coast Countries, the Pacific Rim Countries, South America and anywhere else we either sell or plan to sell cigarettes." 68

INTERNATIONAL VENTILATION

STANDARDS-ISO/TC 205

In addition to consumer products, standards are also utilised to determine air and water quality. For example, the indoor air quality in office buildings is determined according to a set of standards which in turn are used to guide health and safety policies and regulations. In the USA, the American Society of Heating, Refrigerating and Air Conditioning Engineers (ASHRAE) is the organisation appointed by the American National Standards Institute (ANSI) to address indoor air quality standards. In turn, ISO relies on ANSI/ASHRAE standards to develop international air quality standards.

A less discussed fact is the tobacco industry involvement with ISO's technical committee 205-building environment design, mainly with its working group 4: indoor air quality. Given the priority the industry has given in the past few years to the issue of regulation of indoor smoking, this committee is likely to assume a greater importance in the industry's view. The tobacco industry documents provide ample evidence of the industry's interest and influence on ISO/TC 205 and on ventilation and indoor air quality standards. ${ }^{39} 48$ 77-80 An in-depth discussion of these documents is beyond the scope of this paper. However, it is noteworthy that in the future, the industry is likely to exert greater pressure on ISO/TC 205. Until the year 2000, the international standard for indoor air quality has been essentially the same as ASHRAE standard 62-1989. (ASHRAE has revised standard 62-1989, which is now standard 62-1999, with addenda $62 \mathrm{c}-\mathrm{f}$ approved and others still under review. It provides stricter ventilation standards for separating ETS areas from ETS-free areas. It will be interesting to see if ISO will adopt the revised standard.) $)^{81}$

\section{Discussion}

The tobacco industry dominates the process of tobacco and tobacco products standard setting to advance its political and commercial needs, therefore pre-empting the passage of regulatory policies that would indeed protect the health of the public. In the area of cigarettes and other tobacco products, the establishment of international standards has failed to protect consumers' health and safety, due largely to the influence of the tobacco industry. One of the areas where the overarching influence of the tobacco industry is most blatant is in the determination of tar and nicotine yield in cigarette smoke. For several decades the tobacco industry has been de facto responsible for determining the ISO standards on tobacco and tobacco products. Tar and nicotine measurement based on those standards have been widely used by the industry to promote its products as "mild", "lights" and "ultra-lights", for example, insinuating health benefits from these lower tar and nicotine products, when no health benefits exist. ${ }^{6}{ }^{1516}$ (In 1962, in Canada, the tobacco industry agreed to avoid using tar and nicotine levels in advertising, a deal that fell apart in the mid-seventies, with an increase in the competition for the "light" cigarettes market. ${ }^{82}{ }^{83}$ )

It is clear that ISO standards serve only to rank cigarettes according to the tar and nicotine yield when smoked by a machine and that is not reflective of human smoking. ISO standards on tobacco and tobacco products should not be used to measure the health impact these cigarette smoke components have on the smoker as well as on the environment. There is an urgent and long overdue need for public health professionals to push for meaningful changes in the way tobacco related standards are developed, and how they are used. For example, Koslowski and O'Connor suggested a "two stage" compensating test that would provide a more accurate reading of tar and nicotine yield and of tar/nicotine ratios than the existing methods by not only testing cigarettes under more intense smoking conditions (higher volume puff, shorter interval) but also through blocking filter ventilation. $^{9}$

Health advocates in Canada have already convinced the government that current standards on tobacco are deceptive. Both the British Columbia and federal governments modified the ISO methods to produce more realistic readings of the levels of tar and nicotine and other components yields. The Canadian modification provides a range of yields under regular and intense smoking conditions. It is still just a rank of tar and nicotine level as per machine smoke and not a measure of health effects - it may not be possible to estimate precisely a human exposure, as each smoker will smoke in slightly different ways - but it allows for more accurate information to be provided to consumers. ${ }^{10}$ This is relevant as legislation regarding package labelling 
displaying levels of tar and nicotine is being considered, both in Canada and elsewhere, and in face of the proposed European directive. ${ }^{17}$ The 1999 European directive determines, among other things, that tar levels should not exceed $10 \mathrm{mg}$ and nicotine levels should not exceed $1 \mathrm{mg}$, by the year 2003, according to ISO measurement methods. This is an update from a 1990 European directive limiting the amount of tar to $15 \mathrm{mg}$. To comply with the early directive, the industry changed measuring methods without changing the product, as stated in this 1993 memo from PM's M. Bourlas:

"You already know about the EEC mandate to reduce all deliveries to $15 \mathrm{mg}$. As we knew this was going to happen as early as 1988 , we began to develop a strategy with which to react. The strategy centred around the fact that there existed a number of different testing procedures around the world and it seemed prudent on our part to harmonize them. Speerheaded [sic] by PM Europe, we put together a team represented by 23 different markets (countries) and began the task of standardization. The 3 year effort resulted in a new method (now known as 'new ISO') which reduces the smoke delivery results by about $1 \mathrm{mg}$ at the $16 \mathrm{mg}$ level. The Marlboro sold in the EEC was initially delivering about $15.5 \mathrm{mg}$, prior to any analytical methodology change. When the new system was implemented, the deliveries were around $14.5 \mathrm{mg}$, but remember, no product change ever took place ..." ${ }^{\prime 4}$

It is likely that the tobacco industry has already develop strategies to deal with the new European Directive in a manner that will be most beneficial to its interests, such as changing cigarette design. Thus, continuing to make health policy decisions based on current ISO standards is meaningless and is a step back in the tobacco control and consumers' protection movements.

The final report from the WHO's sponsored meeting "Advancing Knowledge on Regulating Tobacco Products" held in Oslo, Norway in February $2000^{2021}$ acknowledges that:

"FTC/ISO methods currently in use were not intended to measure the biological or epidemiological impact of tobacco products. New methods and protocols must be developed to measure the impact of tobacco products on an individual and population basis. ISO should be urged to ensure that its members recognize and adhere to the principle that ISO/FTC measurement and methods are used to monitor performance and not health impacts of tobacco products."20

The report recommends:

"Ban the use of misleading terms such as "light", "mild", and other words or imagery (including certain brand names) which have the aim or effect of implying a reduced health risk attributable to low tar or nicotine measurements on tobacco products and in advertising/ promotional material.

"Remove tar and nicotine measures derived from ISO/FTC methods from packages. Warning labels to emphasize the addictiveness of tobacco products.

"Discontinue harm reduction strategies based on naïve interpretation of tar and nicotine yield measurements. This means abandoning the strategy of seeking lower nominal tar yields and instead, finding approaches that genuinely reduce harm to nicotine users." ${ }^{20}$

The issue of standard measurement of tobacco products components is likely to gain even more international visibility as the negotiations for the Framework Convention for Tobacco Control advance and include the regulation of tobacco products among its protocols.

Each government could follow Canada's example, but it would be more effective if health professionals and tobacco control groups attempt to participate in the work of ISO, either directly or through a national standard organisation. It is unlikely that every single ISO member will be able to set its own measurement standards, as the tobacco industry knows which is why it prefers to work through international organisations. As stated in a 1990 PM document:

"The main disadvantage of arguing with local authorities is that it is very difficult to find technically competent people and/or that we often have to face the anti-smoking lobby and the debate then becomes emotional. On the other hand, if a 'precooked' solution is proposed by a credible international organisation it is often accepted 'as is' because for the fear of going against international trends." 24

The need for groups other than the tobacco industry to become involved with the work of ISO is even more pressing because, in an attempt to streamline and speed its procedures ISO is considering some procedural changes that will give the tobacco industry greater opportunity to determine international standards:

"ISO committees will in future, subject to certain conditions, have the option of dispensing with the committee stage - the part of the ISO process during which national positions are debated in order to reach consensus within an ISO committeeand with the final approval stage, during which the texts of final standards are submitted for formal approval by the full ISO membership ...

"New deliverables representing the consensus between technical experts in an ISO working group or an international consensus achieved in an ISO committee allow publication of new types of documents, called, respectively, Publicly Available Specification (ISO/PAS), and Technical Specification (ISO/TS). ISO will also provide the possibility for adoption of documents developed outside the ISO system by less transparent and consensual procedures. Such documents, whether developed within or outside the ISO system as ISO/PAS or ISO/TS, must be reviewed every three years and at the second review must either be withdrawn or revised to become full ISO International Standards.”

The time for health groups to act is now. With the knowledge accumulated it is no longer acceptable that claims of lower levels of tar and nicotine be made based on ISO standards measurement methods.

The authors would like to acknowledge the assistance and feedback provided by Francis Thompson, Policy Analyst, Non-Smokers' Rights Association.

1 International Organization of Standardization. What is ISO? ISO, 2000.

2 Byrd G, Robinson J, Caldwell W, et al. Comparison of measured and FTC-predicted nicotine uptake in smokers. Psyured and FTC-predicted nicotine uptake

chopharmacology (Berl) 1995;122:95-103.
3 Byrd G, Davis R, Caldwell W, et al. A further study of FTC yield and nicotine absorption in smokers. Psychopharmacology (Berl) 1998;139:291-9. 


\section{What this paper adds}

It is widely known by public health professionals that the ISO standard methods to measure tar and nicotine content in cigarettes are inadequate to assess the amount of human exposure to these components, underestimating the actual yields. The tobacco industry has taken advantage of the ranking provided by these standards to mislead the public, using labels such as "mild" and "light" for cigarettes that have lower tar and nicotine contents according to the ISO method, implying a non-existent health benefit.

This analysis of internal tobacco industry documents shows how the industry is de facto responsible for setting these standard measurement methods, from the testing development to the approval and publication stages. Based on evidence of industry influence provided by this analysis, this study urges public health authorities to play a larger role in the standard setting arena, and to refuse to use the ISO method as a basis to develop health related regulatory policies. The ISO standard, as is, should not be used to justify policies aiming at protecting the public's health.

4 Bates C, McNeill A, Jarvis M, et al. The future of tobacco product regulation and labeling in Europe: implications for the forthcoming European Union directive. Tobacco for the forthcoming E
Control 1999;8:225-35.

5 Hoffman D, Adams J, Haley N. Reported cigarette smoke values: a closer look. Am f Public Health 1983;73:1050-3.

6 Hurt R, Robertson C. Prying open the door to the tobacco industry's secrets about nicotine: the Minnesota Tobacco Trial. $\mathcal{F} A M A$ 1998;280:1173-81

7 Gaisch HW. 1983. Comments on the methodology of cigarette smoke analysis. October 1983, FdTR SA: Neuchatel, Switzerland. Accessed December 2000, Bates 2028530106, www.pmdocs.com

8 Federal Trade Commission. Cigarette testing: request for public comment. Washington, DC: Federal Trade Commission, 1997:14 pages.

9 Kozlowski L, O'Connor R. Official cigarette tar tests are misleading: use a tow-stage conpensating test. Lancet. 2000;355:2159-61.

10 Health Canada Tobacco Control Programme. Determination of "tar", nicotine and carbon monoxide in mainstream tobacco smoke - official method. Ottawa: Health Canada, 1999:5.

11 Sprinkel F, Carter G. October 20, 1982, Comparison of ISO $\&$ domestic FTC method for the determination of tar for development of cigarettes X8D2CBM,O. Philip Morris:
Richmond, VA. Accessed December 2000, Bates 1000814218/4220, www.pmdocs.com

12 Garman J. 1990. Memo to SC Krausse Re: Comparison Study of FTC/UK Smoking. April 10, 1990, Philip Morris: Richmond, VA. Accessed January 2001, Bates 2053446048, www.pmdocs.com

13 Comparison of Different Smoking Methods. PM Germany, Munich: Accessed December 2000, Bates 2028370321/ 0325, www.pmdocs.com

14 Bourlas M, Dymond H. 1989 Task force for the review of smoking procedures: minutes of the meeting held on
March 2, 1989 in Neuchatel. CORESTA. Accessed Mecember 2000, Bates 2028370307/0310, www.pmdocs.com

15 Kozlowski L, Goldberg M, Yost B, et al. Smokers' misperception of light and ultra-light cigarettes may keep them smoking. Am f Prev Med 1998;15:9-16.

16 Leavell N. The low tar lie. Tobacco Control 1999;8:433-7.

17 Commission of the European Communities. Directive of the European Parliament and of the Council on the approximation of the laws, regulation and administrative provision of the Member States concerning the manufacture, presentation and sale of tobacco products. Brusse

18 Bates C. Implications of European Commission tobacco product and branding regulations proposals-comments. London: ASH-UK, 2000:23.

19 International Union Against Cancer, Association of European Cancer Leagues. Tobacco product regulation briefing paper on proposed EU directive COM (99) 594 . Brussels: European Health Networks; 2000:12.

20 Tobacco Free Initiative. Final report: advancing knowledge on regulating tobacco products. Geneva: WHO, 2000.
21 Anon. Advancing knowledge on regulating tobacco products, Oslo, Norway. Tobacco Control 2000;9:224-6.

22 Yach D, Bettcher D. Globalisation of tobacco industry influence and new global responses. Tobacco Control 2000; 9:206-16.

23 World Health Organization. WHO Framework Convention on Tobacco Control: report of the second meeting of the working group. Geneva: WHO, 2000:15.

24 Boder J. 1990. Memorandum to MC Bourlas Re: Philip Morris and the Scientific Organizations ISO-CORESTA. March 19, 1990, Philip Morris. Accessed February 2000, Bates 2021370246/0248, www.pmdocs.com

25 Wakeham H. 1974 CORESTA Council meeting at the Congress in Montreux, Switzerland. October 17, 1974, Philip Morris USA: Richmond, VA. Memorandum. Accessed June 2000,Bates 1004863711/3713, www.pmdocs.com

26 Cullman H. 1980 Notes CORESTA Council Meeting. June 13, 1980, Philip Morris: Paris, France. Notes, Accessed June 2000, Bates 2001205366, www.pmdocs.com

27 Reif H. 1994 Memorandum to Dr R Carchman and Dr A Kassman Re: Meeting of the WPA. March 18, 1994, Philip Morris: Memorandum. Accessed February 2000, Bates 2028343996/4001, www.pmdocs.com

28 Boralli R. 1991 CORESTA - Letter to W.C. Owen. May 14, 1991, Gallaher Limited: United Kingdom. Letter. Accessed June 2000, Bates 2501294779, www.pmdocs.com

291997 Technical Activity Summary. Philip Morris. Accessed February 2000, Bates 2060565672, www.pmdocs.com

30 Ellis C. 1998 Tar \& Nicotine testing issues, compensation, maximum constituents levels. August 18, 1998, Philip 2060569582, www.pmdocs.com

31 Bourlas M. 1992. Letter to Francois Jacob, Secretary General, CORESTA. December 30, 1992, Philip Morris: Richmond, VA. Letter. Accessed June 2000, Bates 2028654000, www.pmdocs.com

32 No date ISO/ANSI. Philip Morris. Accessed February 2000, Bates 2028897025/7026, www.pmdocs.com

33 No date Technical Committee TC 126. Philip Morris Accessed February 2000, Bates 2028652539/2540, www.pmdocs.com

34 ISO/TC 126 N 535. 1995 Draft Report of the Ninteenth Plenary Meeting held in Cape Town (South Africa) on 22 and 23 February 1995. April, 1995, Philip Morris: Report. Accessed June 2000, Bates 51749 6783/6810, www.rirtdocs.com

35 TCRC Policy Committee. 1997 Report of the TCRC Policy Committee 51st Tobacco Chemists Research Conference (September 15, 1997, Winston-Salem). TCRC/Philip Morris. Accessed February, 2000, Bates 2063579080/
9082, www.pmdocs.com

36 Ogden MW. 1998 Minutes of CORESTA's ETS SubGroup Meeting, Brussels, Belgium. May 29, 1998, RJR/CORESTA. Accessed February 2000, Bates 2502091538/1540, www.pmdocs.com

37 ISO. 1989 Resolution No 171 - Precision of smoking procedure. Philip Morris. Accessed February, 2000, Bates 2028531324, www.pmdocs.com

381990 Contact Profile. HER, S\&T, FTR/PM Neuchatel. Philip Morris: Neuchatel, Switzerland. Accessed February 2000, Bates 2028390226/0236, www.pmdocs.com

39 Ogden MW. 1997 Minutes of CORESTA's ETS SubOgden MW. 1997 Minutes of CORESTA's ETS Sub-
Group Meeting, Paris, France, April 23-24, 1997. RJR Tobacco/CORESTA. Accessed February, 2000, Bates 2063651215/1220, www.pmdocs.com

40 Letter to Mr Peter I Adams. January 14, 1981, Philip Morris: Letter. Accessed February 2000, Bates 2000515528, www.pmdocs.com

41 Letter to Mr Peter I Adams. July 11, 1984. Letter. Accessed March 2000, Bates 2000516157, www.pmdocs.com

42 Patent No. GB 2122264A: Ventilated filter cigarette. December 23, 1983, PLC IG: Patent, Accessed February 2000, Bates 2026361312, www.pmdocs.com

43 Adams P. 1982 Letter to CORESTA Technology Group. July, 1982, CORESTA: Letter. Accessed March 2000, Bates 1003722027, www.pmdocs.com

44 Scientific Liaison Working Group of the EIG. 1994 minutes of the meeting. February 9, 1994, EIG: London, UK. Minutes. Accessed March 2000, Bates 2028425015/5018, www.pmdocs.com

45 Scientific Liaison Working Group of the EIG. 1994 draft minutes of the 28th meeting. June 20, 1994, EIG: London, UK. Minutes. Accessed March 2000, Bates 2026219657/ 9661, www.pmdocs.com

46 Papentus H. 1997 To all members of the Scientific Commission and Francois Jacob, Secretary General,
CORESTA. July 30, 1997, Rothmans of Pall Mall (International) Limited: Letter. Accessed February 2000, Bates 2060568331A/8332, www.pmdocs.com

47 CORESTA Scientific Policy Committee. 1997 Minutes of the meeting of the Scientific Policy Committee on June 13, 1997. Philip Morris/CORESTA. Accessed February, 2000, Bates 2060547077/7083, www.pmdocs.com

481998 Meeting of the Scientific Commission (WPA) of the German Cigarette Association (VDC). June 17, 1998, Philip Morris: Bonn, Germany. Notes. Accessed February 2000, Bates 2060568395, www.pmdocs.com

491998 Abbreviated report on the main topics of the meeting-Personal notes taken at meeting. May 06, 1998, 2000, Bates 2060568409/8410, www.pmdocs.com 
50 Ward M. 1997 Briefing on plant genetic modification with special reference to tobacco-Presentation to CORESTA Board. June 11, 1997, CORESTA/Philip Morris:
Lausanne, Switzerland. Accessed June 2000, Bates Lausanne, Switzerland. Accessed JA

$51 \mathrm{ISO} / \mathrm{TC}$ 126. 1989 Environmental tobacco smokedetermination of nicotine by gas-chromatographic method. November 8, 1989, Philip Morris: Switzerland. Proposal. Accessed February 2000, Bates 2028532448/ 2450, www.pmdocs.com

52 ISO/TC 126. 1990 ISO/DIS 10315: Cigarettesdetermination of nicotine in smoke condensates - gaschromatographic method. March 14, 1990, Philip Morris: Switzerland. Accessed June 2000, Bates 2031400787 0792, www.pmdocs.com

531997 Technical Activity Summary. Philip Morris. Accessed February 2000, Bates 2060565685, www.pmdocs.com

54 HER. 1998 Meeting of the Scientific Commission (WPA) of the German Cigarette Association (VDC). September 28, 1998, Philip Morris: Bonn, Germany. Notes. Accessed February 2000, Bates 2060554526, www.pmdocs.com

55 Scientific Liaison Committee of TAC' SC. 1991 Minutes of the 13th meeting. January 23, 1991, TAC: Minutes.
Accessed March 2000, Bates 2028465792/5796, www.pAccessed $M$

56 Reif H. 1998 Memorandum to Richard Carchman: monthly activities 1st through 31st May, 1998. Philip Morris: Accessed February, 2000, Bates 2060565811/5814, www.pmdocs.com

57 CORESTA Outgoing Scientific Commission. 1996 Minutes of the Outgoing Scientific Commission Meeting, November 3rd 1996, Japan. CORESTA. Accessed February 2000, Bates 51880 5267/5273, www.rirtdocs.com

58 Deltafina. 1990 (For your information). Philip Morris. Accessed February 2000, Bates 2025591729/1730, www.pmdocs.com

59 CORESTA Scientific Commission. 1991 Minutes of the meeting of the Scientific Commission held on May 16th meeting of the Scientific Commission held on May 16th and 17th, 1991 (Spain). RJR Tobacco/CORESTA. Ac-
cessed February, 2000, Bates 50797 3273/3281, www.rjrtdocs.com

60 CORESTA Scientific Commission. 1984 Meeting of the Sientific Commission, 15-16 May 1984, London. CORESTA. Accessed February, 2000, Bates 508817124 7137, www.rirtdocs.com

61 Bourlas M. 1989 Memorandum to Ronald Lively Re: CORESTA Board meeting-Rome. October 27, 1989, Morris P: Memo. Accessed December 2000, Bates 2500045751/5752, www.pmdocs.com

62 Mueller DL. 1993 CORESTA Agro-Chemicals Advisory Committee Meeting in October 3, 1993, in Budapest, Hungary. Philip Morris/CORESTA. Accessed February, 2000, Bates 2028473840, www.pmdocs.com

63 Covington M. 1974 Memo to Hugh Cullman, Subject: CORESTA Council Meeting, June 28, 1974. June 26, 1974, Philip Morris: New York. Memorandum. Accessed 1974, Philip Morris: New York. Memorandum. Access

64 PME Science and Technology 1983 Defensive Activities, Objectives and Strategies: 1983-1988, 22 April, 1983. Objectives and Strategies: 1983-1988, 22 April, 1983.
Philip Morris. Accessed February, 2000, Bates Philip Morris. Accessed February

65 Baskevitch N. No date. Dilution of cigarettes at the filter level. DeMalaucene Papetiere: Paris, France. Accessed on February 2001, Bates 2504087458/7475, www.pmdocs.com

66 Hauni-Technil 10 "The manufacture of filter cigarettes with dilution zones." September 1978, Hauni-Werke KCKG: Hamburg, Germany. Accessed February 2001, Bates 2504087476/7496, www.pmdocs.com
67 Channel ventilated cigarettes-Barclay: A report on the legal developments. March 23, 1987, Philip Morris. Accessed February 2001, Bates 2501006188/6192, www.pmdocs.com

68 Cox R. 1990 Recommendations for PM USA positions on pending standards issues. May 9, 1990, Philip Morris USA: Richmond, VA. Accessed June 2000, Bates 2021370249/0254, www.pmdocs.com

69 Lopes F. 1986 ISO Meeting. September 19, 1986, FTR Research and Development: Neuchatel, Switzerland. Accessed February 2000, Bates 2022220257/0260, www.pmdocs.com

70 ISO/DIN. 1985 draft report of the thirteenth plenary meeting. June, 1985, ISO/TC 126: Switzerland. Accessed June ing. June, 1985, ISO/TC 126: Switzerland. Acce
2000, Bates 2028456530, www.pmdocs.com

71 Gaisch H. 1986 Memo to Dr M Hausermann, subject: ISO meeting in Turkey. October 1, 1986, FTH Science and Technology: Neuchatel, Switzerland. Memo. Accessed February 2000, Bates 2028457027/7033, www.pmdocs.com

72 Bourlas M. 1988 ISO TC/126 Meeting, Beijing, China. May 2, 1988, FTR Research and Development: Neuchatel, Switzerland. Accessed June 2000, Bates 2001160616 0618, www.pmdocs.com

73 Bible G. 1988 Memo to RA Hutchinson /A Whist, subject: ISO-TC 126 meeting. March 15, 1988, Philip Morris: 2501029664, www.pmdocs.com

74 Boder J. 1989 BATH-Summary of agreement reached during the three meetings. April 5, 1989, FTR Research and Development: Nuechatel, Switzerland. Memo. Accessed June 2000, Bates 2500046043/6044, www.pmdocs.com

75 Draft 6 - 27 Sept. 1989 Agreement. September 27, 1989. Accessed June 2000, Bates 2500045805/5807, www.pmdocs.com

761989 Agreement. November 21, Switzerland. Accessed June 2000, Bates 2500045705/5707, www.pmdocs.com

77 International Ventilation Standards. January 3, 1994, Philip Morris. Accessed February 2000, Bates 2029041219/ 1221, www.pmdocs.com

78 Logue M. 1994 Memo to Jan Goodheart, Mary Pottorff and Mat Winokur re: ISO/TC 205. February 1, 1994, Philip Morris: New York. Memo. Accessed February 2000, Bates 2024210598, www.tobaccodocuments.org

79 Measurement Core Group. 1998 Summary of measurement core group meeting, Atlanta, April 16-17, 1998. Philip Morris. Accessed February, 2000, Bates 2060566046/ 6049, www.pmdocs.com

80 Cammer P. 1989 Minutes of meeting, board of directors, November 1, 1989. Business Council on Indoor Air: Washington DC. Minutes. Accessed February 2000, Bates 2023920667/0669, www.pmdocs.com

81 American Society of Heating Refrigeration and Air Conditioning Engineers, Inc. Ventilation for acceptable indoor air quality. Atlanta: ASHRAE, 1999.

82 Kennedy M. Tobacco firms colluded to hide tar, nicotine data. The Ottawa Citizen. Ottawa; 2000.

83 Policy statement by Canadian Tobacco Manufacturers on the content of tar, nicotine and other smoke constituents that may have similar connotations. October 12, 1962, Philip Morris: Canada. Accessed June 2000, Bates 2024994264, www.pmdocs.com

84 Bourlas M. 1993 Memo to P Alvis, subject: Marlboro Product Quality in the EEC/ Tar Reduction. April 19, 1993, Philip Morris. Accessed June 2000, Bates 2500055616/ 5616A, www.pmdocs.com 